\title{
Compensatory dynamics and the stability of phytoplankton biomass during four decades of eutrophication and oligotrophication
}

\author{
Marc C. Jochimsen, ${ }^{1}$ Reiner \\ Kümmerlin, ${ }^{2}$ and Dietmar \\ Straile ${ }^{1 *}$ \\ ${ }^{1}$ Limnological Institute, University \\ of Konstanz, Konstanz, 78464, \\ Germany \\ ${ }^{2}$ Institut für Seenforschung, \\ Langenargen, 88085, Germany \\ *Correspondence: E mail: dietmar. \\ Straile@uni konstanz.de
}

\begin{abstract}
The link between compensatory dynamics and regime shifts is not well understood. We analyse a regime shift in phytoplankton in a large lake with respect to: (1) environmental forcing and (2) the type of dynam ics (compensatory or synchronous) between phytoplankton groups. The regime shift in phytoplankton was related to gradual changes in nutrient levels, but unrelated to an almost concurrent shift in climatic condi tions. The relationship between total phytoplankton biomass and phosphorus concentrations was sigmoid. Trajectories of phytoplankton biomass and community dynamics suggest that eutrophication effects can successfully be reversed when management efforts decrease nutrient loading to a level sufficiently low to overcome community resilience. The regime shift was associated with a loss of biomass compensation and compensatory dynamics among the phytoplankton groups. This suggests that the type of interactions is important for a better understanding of the existence and shape of nonlinear responses of phytoplankton biomass to environmental change.
\end{abstract}

\section{Keywords}

Biomass compensation, climate warming, community dynamics, functional diversity, nonlinear response, regime shift, resilience, reversibility of anthropogenic change, trophic state.

\section{INTRODUCTION}

Human activity during the past century has put increasing stress on natural ecosystems in almost all habitats on the earth (Vitousek $e t$ al. 1997; Jackson et al. 2001; Smith \& Schindler 2009). During the last decade, it has become increasingly clear that ecosystem responses to stress are often nonlinear and may involve abrupt changes or even catastrophic shifts after critical environmental conditions have been surpassed (Scheffer et al. 2001). The specific response trajectories to environmental change, i.e. smooth, abrupt or catastrophic, also have major implications for the system's ability to recover from stress or disturbance (Duarte et al. 2009).

The response of food webs and communities to environmental change is mediated by their properties, including their taxonomic and functional diversity and types of species interactions. For exam ple, important factors and processes contributing to the stability of ecosystem functioning are biodiversity via, e.g. portfolio effects (Schindler et al. 2010) and response diversity (Elmqvist et al. 2003) and the existence of compensatory dynamics between different pop ulations (Gonzalez \& Loreau 2009). In a changing environment, abundance decreases of species susceptible to a specific environ mental driver may be compensated by increased growth of less sen sitive taxa. An abrupt shift in ecosystem response to environmental change therefore may be the consequence of the decline of the compensatory capacity of the community. While there are studies showing that compensatory dynamics in response to environmental change or variability exist in natural communities (Fischer et al. 2001; Bai et al. 2004; Gonzalez \& Loreau 2009), there is hardly any study in which fast shifts in ecosystem states are linked to the exis tence, decrease and final collapse of compensatory dynamics.

Lake communities provide classical examples for abrupt shifts in ecosystem status and multiple attractors caused by changes in nutrient influx (Scheffer et al. 2001; Scheffer \& Carpenter 2003; Car penter 2005). Resilience of phytoplankton communities to respond to management efforts reducing nutrient inflow into lakes has been observed in many studies (e.g. Jeppesen et al. 2005). Typically, responses of phytoplankton biomass to nutrient reductions lagged behind several years and presumably occurred only once nutrient loading or concentration fell below a critical level. The total phyto plankton biomass and its dynamics are aggregate, respectively, emer gent properties of the dynamics of individual phytoplankton taxa. Hence, analysing the dynamics of different phytoplankton groups is crucial for understanding the dynamics and responses of total phyto plankton biomass. Phytoplankton communities are known to be rich in both species and functional types, and many laboratory experi ments have shown that they are strongly structured by competition and can show a high response diversity (e.g. Sommer 1989 and refer ences therein). A resilience of phytoplankton biomass to directly track decreasing nutrient levels might suggest that declines of sensi tive species are compensated by opposing responses of more tolerant taxa, thereby buffering the effects of environmental change. A time delayed response of total biomass might then indicate that the remaining capacity of the community to compensate for biomass declines of some taxa is not strong enough any more to maintain community stability. Here, we test this hypothesis with the analysis of an exceptional long term data set of phytoplankton sampled in Lake Constance over 43 study years. Lake Constance is of outstand ing importance as a recreational site and as one of the most impor tant drinking water reservoirs in Europe, providing water for about 4 million people. Severe eutrophication of the lake during post war in dustrialisation was stopped at the end of the 1970s, and finally reversed with a comprehensive sewage purification programme for the whole catchment area at a cost of more than 4 billion US $\$$. The 43 years considered in this study cover the last 15 years of the 
eutrophication period of Lake Constance, its peak and 28 year period of subsequent oligotrophication. Hence, these data provide a unique possibility to examine: (1) the potential resilience of phytoplankton response to nutrient changes, (2) the role of phytoplankton interac tions in this response and (3) whether this response was characterised by hysteresis, i.e. differing biomass and community trajectories during eutrophication and oligotrophication.

\section{MATERIAL AND METHODS}

\section{Study site and sampling}

Lake Constance is a deep $\left(z_{\text {mean }}=101 \mathrm{~m}\right)$ warm monomictic lake in central Europe. As a proxy of the lake's trophic status in each specific sampling year, we used the total phosphorus concentration measured during the February/March mixing period $\left(\mathrm{TP}_{\mathrm{MIX}}\right.$, Fig. 1a). In total, 1040 phytoplankton samples were taken from 1965 to 2007 at the centre of Upper Lake Constance. For details on phytoplankton sampling procedures and measurements of TP and water temperature (W'T), see Appendix S1. Phytoplankton spe cies were grouped into eight major taxonomic groups: Cyanobacte ria, Chrysophyta, Cryptophyta, Dinophyta, Chlorophyta, Conjugales and two orders of Bacillariophyceae, Centrales and Pennales. All statistical analyses were done at this taxonomic level. This phyloge netic grouping is a close analogue to a functional grouping, as these groups differ in important functional features like size, motility, nutrient requirements and uptake kinetics and importance of differ ent nutrition modes (photoautotrophy or mixotrophy) (Litchman et al. 2007).

\section{Statistical methods}

We tested for the occurrence of a regime shift in our time series using Rodionov's regime shift detection method (RRSD, Rodionov 2004). As this test indicated a regime shift for WT and phytoplank ton biomass, we fitted these long term developments with a modified logistic function, which connects two stable periods by a transitional period. The relationship of annual mean phytoplankton biomasses (and biomass lagged by 2 years) to $\mathrm{TP}_{\mathrm{MIX}}$ and WT was analysed with generalised additive models (GAMs) (Wood 2006). To analyse whether phytoplankton groups displayed compensatory, independent or synchronous dynamics during distinct time periods, we calculated two related metrics, the variance ratio (VR) (Schluter 1984) and $\phi_{\mathrm{p}}$ (Loreau \& Mazancourt 2008). Both metrics relate the variance of the community biomass to the variances of the biomasses of individual taxa within the community. A VR of 1 occurs when taxa fluctuate independently or when positive and negative covariances between species neutralise each other exactly (Gonzalez \& Loreau 2009). A $\mathrm{VR}>1$ indicates that the sum of covariances among taxa is positive (synchronous dynamics), whereas a VR $<1$ (compensatory dynamics) occurs when the sum of covariances is negative. In contrast, $\phi_{\mathrm{P}}$ is standardised between 0 and 1, denoting perfect compensatory and
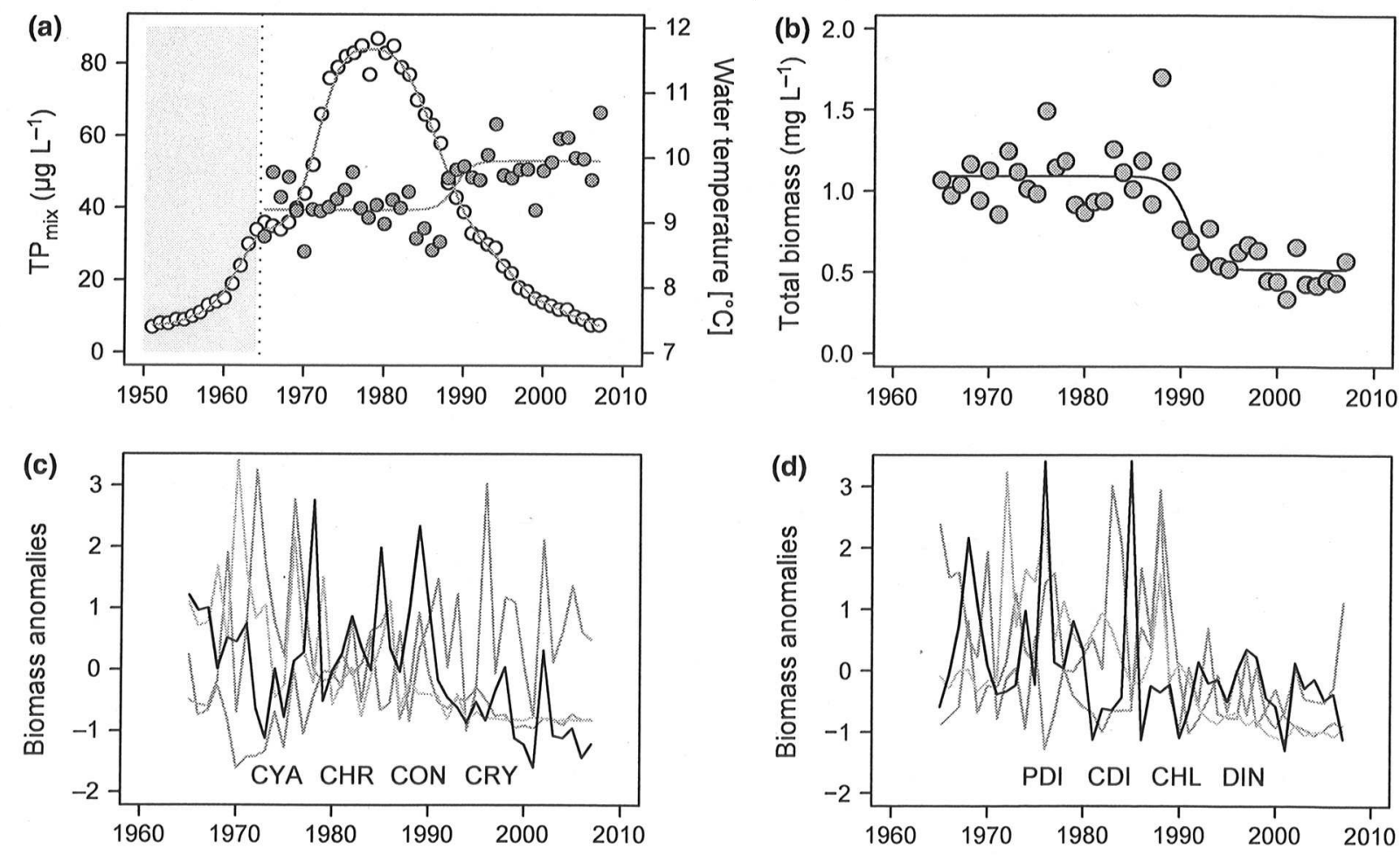

Figure 1 Temporal development of (a) total phosphorous concentrations during winter mixis (open symbols) and annual average water temperatures (blue line and dots), (b) total phytoplankton biomass, (c) anomalies of the biomasses of cyanophytes (CYA), chrysophytes (CHR), Conjugales (CON) and cryptophytes (CRY) and (d) biomasses of pennate diatoms (PDI), centric diatoms (CDI), chlorophytes (CHL) and dinophytes (DIN). No phytoplankton data were available for the time period shaded in panel 1a. The temporal development of water temperature and phytoplankton biomass was fitted with a modified logistic function: $Y_{t} a+b \frac{e^{t}, t}{t+t^{t}}$ with parameter estimates of a $9.95 \pm 0.09 \mathrm{SE}, \mathrm{b} \quad 0.76 \pm 0.12 \mathrm{SE}$ and $\mathrm{T} \quad 1989 \pm 1 \mathrm{SE}$ for water temperature and a $0.51 \pm 0.05 \mathrm{SE}, \mathrm{b} \quad 0.58 \pm 0.06 \mathrm{SE}$ and T $1991 \pm 1 \mathrm{SE}$ for phytoplankton biomass. 
perfect synchronous dynamics respectively. We calculated VR and $\phi_{\mathrm{P}}$ for the total time series and for subperiods. To analyse to which extent these metrics are scale dependent, i.e. sensitive to the length of the analysis period, and the range of environmental conditions encountered, we performed an 'expanding window' analysis: we first calculated both community metrics for the time period from 1965 to 1975. Then the calculation window was continuously expanded by one additional study year until the full time series was included. The temporal dynamics of the type of community interactions during the study period were investigated via performing an 11 year 'moving window' analyses of VR and $\phi_{P}$. Bray Curtis dissimilarities between the study years were used as a basis for non metric multidimensional scaling (NMDS) ordination and to test for relationships between community dissimilarity and differences in $\mathrm{TP}_{\mathrm{MIX}}$ between years (Mantel test). For details on the calculation of community metrics and statistical analyses, see Appendix S1.

\section{RESULTS}

During the first 15 years of the study period, phosphorus concen trations during the winter mixing period (TP $\mathrm{TIX}_{\mathrm{X}}$ ) increased twofold to a maximum of $87 \mu \mathrm{g}$ TP $L^{-1}$, followed by a subsequent approxi mately tenfold decrease towards the most recent years (Fig. 1a). Epilimnetric WT increased during the study period $(\tau=0.32$, $P<0.005)$. However, this increase was not gradual, but included a rather steep change in 1988 (Fig. 1a, RRSD, $P<0.0001$ ). The annual average of phytoplankton biomass was remarkably stable during the first two decades of the study period (Fig. 1b). Thereaf ter, biomass declined within a few years approaching a new phase of stable, but lower biomass since the mid 1990s. RRSD suggests the existence of one regime shift in the time series occurring in $1990(P<0.0001)$, i.e. 2 years after the shift of WT. The timing of the biomass shift was also supported when fitting a modified logis tic function, which indicated an inflection point in 1991 (Fig. 1b) and stable biomasses until approximately 1986, and again from approximately 1996 onwards. These two periods of relative biomass stability will be referred to in the following as 'high biomass period' (HBP) and 'low biomass period' (LBP) respectively. Taxonomic groups differed strongly in their temporal dynamics showing bio mass decreases (cyanophytes, chlorophytes, conjugatophytes and centric diatoms), biomass increases (chrysophytes) as well as com plex dynamics (pennate diatoms, cryptophytes and dinophytes) (Fig. 1c,d). However, with the exception of pennate diatoms, bio masses of all groups differed significantly between HBP and LBP $(t$ tests, all $P<0.05)$

Biomasses of all phytoplankton taxa with the exception of di nophytes were significantly related to $\mathrm{TP}_{\mathrm{MIX}}$ (Table 1 , Appendix S2), but not to WT in the full model (Table 1). Removing $\mathrm{TP}_{\mathrm{MIX}}$ from the models strongly reduced deviances and changed the e.d. f.'s, i.e. the form of the biomass W'T relationships (Table 1). In contrast, removing W'T from the full models did neither signifi cantly reduce deviances nor changed the e.d.f.'s of the biomass $\mathrm{TP}_{\mathrm{MIX}}$ relationships (Table 1). This suggests that the significance of W'T biomass models for some taxa is spurious and most likely results from the negative correlation between $\mathrm{TP}_{\mathrm{MIX}}$ and WT $(r=-0.6, P<0.001)$.

The type of biomass relationships with $\mathrm{TP}_{\mathrm{MIX}}$ varied strongly between the different algal groups, i.e. from a linear biomass increase with increasing $\mathrm{TP}_{\mathrm{MIX}}$, saturating or sigmoid relationships,
Table 1 Summary of GAMs relating phytoplankton biomasses of total phytoplankton (TOTAL) and of the different phytoplankton groups to $\mathrm{TP}_{\mathrm{MIX}}$ and W'T (full model) and to $\mathrm{TP}_{\mathrm{MIX}}$ and WT separately

\begin{tabular}{|c|c|c|c|c|c|c|}
\hline \multirow[b]{2}{*}{ Taxon } & \multirow[b]{2}{*}{ model } & \multicolumn{2}{|c|}{$\mathrm{TP}_{\mathrm{MIX}}$} & \multicolumn{2}{|l|}{ W'T } & \multirow[b]{2}{*}{ dev. expl. } \\
\hline & & e.d.f. & $F$ & e.d.f. & $F$ & \\
\hline \multirow[t]{3}{*}{ TOTAL } & full & 2.89 & $33.3 * * *$ & \multirow[t]{2}{*}{2.8 e 05} & \multirow[t]{2}{*}{$3 \mathrm{e} 06 \mathrm{~ns}$} & $75.8 \%$ \\
\hline & $\mathrm{TP}_{\mathrm{MIX}}$ & 2.89 & $33.3 * * *$ & & & $75.8 \%$ \\
\hline & W'T & & & 0.94 & $16.45 * * *$ & $29.8 \%$ \\
\hline \multirow[t]{3}{*}{ CYA } & full & 2.54 & $21.9 * * *$ & \multirow[t]{2}{*}{0.69} & \multirow[t]{2}{*}{$2.26 \mathrm{~ns}$} & $69.9 \%$ \\
\hline & $\mathrm{TP}_{\mathrm{MIX}}$ & 2.43 & $26.2 * * *$ & & & $67.2 \%$ \\
\hline & W'T & & & 1.8 & $4.28 *$ & $23.7 \%$ \\
\hline \multirow[t]{3}{*}{ CHR } & full & 0.91 & 10.2 ** & \multirow[t]{2}{*}{7.1 e 06} & \multirow[t]{2}{*}{$3 \mathrm{e} 06 \mathrm{~ns}$} & $21.3 \%$ \\
\hline & $\mathrm{TP}_{\mathrm{MIX}}$ & 1.60 & $5.2 * *$ & & & $23.5 \%$ \\
\hline & WT & & & 1.39 & $2.7 \mathrm{~ns}$ & $14.4 \%$ \\
\hline \multirow[t]{3}{*}{$\mathrm{CDI}$} & full & 0.98 & $46.8 * * *$ & \multirow[t]{2}{*}{$1.8 \mathrm{e} 06$} & \multirow[t]{2}{*}{$2 \mathrm{e} 07 \mathrm{~ns}$} & $53.8 \%$ \\
\hline & $\mathrm{TP}_{\mathrm{MIX}}$ & 0.98 & $46.8 * * *$ & & & $53.8 \%$ \\
\hline & WT & & & 1.81 & $4.70 *$ & $24.4 \%$ \\
\hline \multirow[t]{3}{*}{ PDI } & full & 2.97 & $2.8 *$ & \multirow[t]{2}{*}{1.51} & \multirow[t]{2}{*}{$2.02 \mathrm{~ns}$} & $36.1 \%$ \\
\hline & $\mathrm{TP}_{\mathrm{MIX}}$ & 3.37 & $3.1 *$ & & & $30.2 \%$ \\
\hline & WT & & & 1.64 & $1.7 \mathrm{~ns}$ & $12.7 \%$ \\
\hline \multirow[t]{3}{*}{ DIN } & full & 0.65 & $1.9 \mathrm{~ns}$ & \multirow[t]{2}{*}{1.5 e 06} & \multirow[t]{2}{*}{8 e $08 \mathrm{~ns}$} & $5.83 \%$ \\
\hline & $\mathrm{TP}_{\mathrm{MIX}}$ & 0.65 & $1.9 \mathrm{~ns}$ & & & $5.83 \%$ \\
\hline & $W^{\prime} T$ & & & 4.40 & 2 e $05 \mathrm{~ns}$ & $0.00 \%$ \\
\hline \multirow[t]{3}{*}{ CRY } & full & 2.38 & $11.8 * * *$ & \multirow[t]{2}{*}{2.6 e 05} & \multirow[t]{2}{*}{$2 \mathrm{e} 06 \mathrm{~ns}$} & $49.0 \%$ \\
\hline & $\mathrm{TP}_{\mathrm{MIX}}$ & 2.38 & $11.8 * * *$ & & & $49.0 \%$ \\
\hline & W'T & & & 0.89 & $8.14 * *$ & $18.1 \%$ \\
\hline \multirow[t]{2}{*}{ CHL } & full & 3.12 & $45.5^{* * *}$ & \multirow[t]{2}{*}{0.98} & \multirow[t]{2}{*}{$0.51 \mathrm{~ns}$} & $86.8 \%$ \\
\hline & $\mathrm{TP}_{\mathrm{MIX}}$ & 3.07 & $60.0 * * *$ & & & $85.7 \%$ \\
\hline$\theta$ & $W^{\prime} T$ & & & 2.23 & 7.91 *** & $39.0 \%$ \\
\hline \multirow[t]{3}{*}{$\mathrm{CON}$} & full & 2.77 & $14.8^{* * *}$ & \multirow[t]{2}{*}{0.67} & $2.04 \mathrm{~ns}$ & $71.4 \%$ \\
\hline & $\mathrm{TP}_{\mathrm{MIX}}$ & 2.84 & $24.7 * * *$ & & & $69.7 \%$ \\
\hline & WT & & & 0.96 & $25.86 * * *$ & $39.5 \%$ \\
\hline
\end{tabular}

Abbreviations used for phytoplankton groups are: cyanophytes (CYA), chrysophytes (CHR), centric diatoms (CDI), pennate diatoms (PDI), dinophytes (DIN), cryptophytes (CRY), chlorophytes (CHL) and Conjugales (CON). For all variables in the models, the estimated degrees of freedom (e.d.f.) and $\mathrm{F}$ values with corresponding significance levels $(* * * P<0.001, * * P<0.01, * P<0.05$, n.s. $P>0.05)$ are shown. Model performance is indicated by the deviance explained (dev. expl.) of the respective models.

decreases with increasing $\mathrm{TP}_{\mathrm{MIX}}$, to a complex relationship with a biomass maximum at intermediate $\mathrm{TP}_{\mathrm{MIX}}$ values (Appendix S2). Total phytoplankton biomass (Fig. 2), i.e. the aggregated property of the biomass responses of the individual taxa, was sigmoidally related to $\mathrm{TP}_{\mathrm{MIX}}$ (Fig. 2, GAM, e.d.f. $=2.89, P<0.0001$ ), but no relationship with WT was evident (e.d.f. $=2.8 \times 10^{-6}$ ). We also found no convincing evidence for an influence of WT on annual average phytoplankton biomasses when we considered a time lag of biomass of 2 years to account for the shift in WT 2 years before the total phytoplankton biomass shift (Appendix S3).

High biomass period and LBP differed with respect to: (1) the existence of compensatory dynamics and (2) the importance of $\mathrm{TP}_{\mathrm{MIX}}$ for structuring the phytoplankton community. During HBP, the phytoplankton community showed compensatory dynamics (Fig. 3a) and community change was significantly related to changes in $\mathrm{TP}_{\mathrm{MIX}}$ (Fig. 3b), whereas during LBP, phytoplankton group bio masses varied independently based on VR, but synchronously based on $\phi_{\mathrm{P}}$ (Fig. 3a) and their changes were not significantly related to changes in $\mathrm{TP}_{\mathrm{MIX}}$ (Fig. 3b). Considering the total time series, phy toplankton groups showed significant synchronous dynamics (Fig. 3a) and community dynamics were strongly related to $\mathrm{TP}_{\mathrm{MIX}}$ 


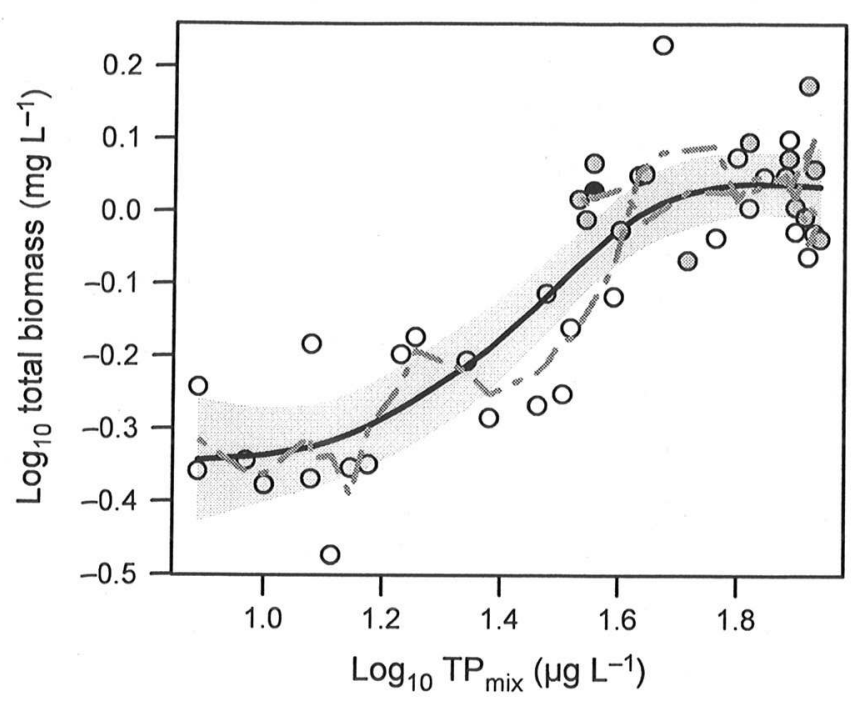

Figure 2 Relationship between $\log _{10}$ transformed total phosphorus concentrations and total phytoplankton biomass. The solid line represents the fit of the generalised additive model (see Table 1). The grey areas represent \pm 2 SE of the fit. The dashed grey line indicates the temporal trajectories based on a 3-year moving average. The black dot represents the start of the study period (1965), the grey dots the years of eutrophication and the white dots the subsequent years of oligotrophication.

dynamics (Fig. 3b). Differences in $\phi_{\mathrm{p}}$ between periods paralleled those observed for VR.

The 'expanding window' analysis shows VRs around 0.5 up to a window, which encompasses the first half of the study period until 1987 (Fig. 3c). The further inclusion of study years afterwards resulted into continuously increasing VRs shifting the dynamics from compensatory towards independent dynamics. Note that compensatory dynamics started to cease in importance prior to the phytoplankton regime shift. After 1997, overall dynamics among the phytoplankton community components became significantly syn chronous. The 11 year 'moving window' analysis supports this over all trend towards higher VR values (Fig. 3d). However, this analysis suggests more complex dynamics also within the HBP and LBP and strongest synchronous dynamics during the early 1990s, i.e. dur ing the transition between HBP and LBP. The dynamics of $\phi_{\mathrm{P}}$ par alleled those of VR, both in the moving window and expanding window analyses (data not shown). Note that both the 'expanding window' and 'moving window' analyses show a rather large increase of VR in 1988 (Fig. 3c, d), which is caused by the peak of total bio mass occurring in this year (Fig. 1b). Overall VR dynamics were, however, not strongly influenced by this specific year, which can be demonstrated by substituting the biomass values of 1988 with aver age values from 1987 and 1989 (see Appendix S4).

Biomass trajectories, shown as 3 year running means (Fig. 2, Appendix S2), suggest that biomass responses to $\mathrm{TP}_{\mathrm{MIX}}$ of all taxo nomic groups at $\mathrm{TP}_{\mathrm{MIX}}$ values $>40 \mu \mathrm{g} \mathrm{L}^{-1}$ did not depend on whether $\mathrm{TP}_{\mathrm{MIX}}$ was increasing or decreasing. This is supported by the residuals of the GAM smooths, which did not exhibit a signifi cant temporal trend (all $P>0.05$, except for Conjugales and Cryp tophytes). Likewise, analyses at the community level do not suggest
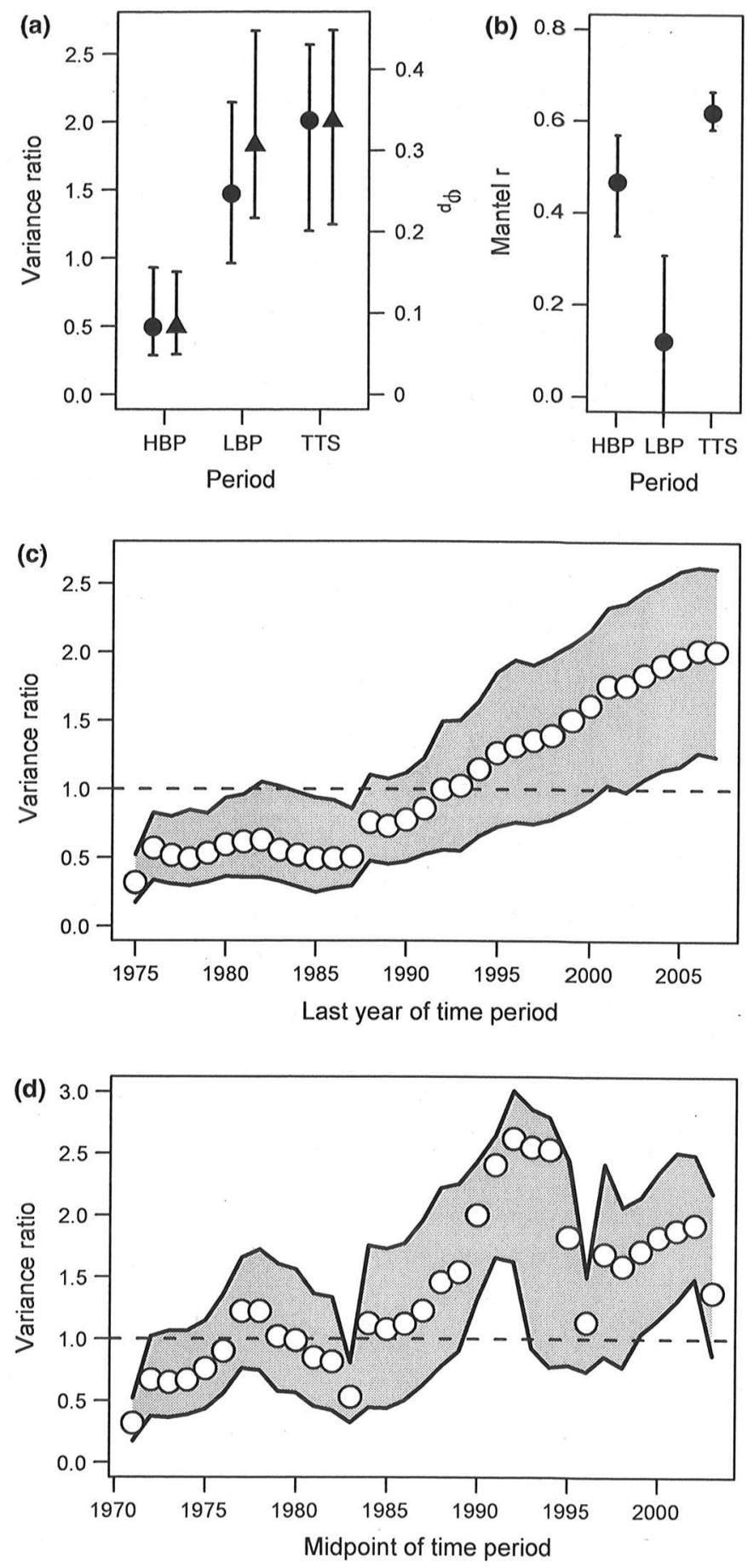

Figure 3 (a) Variance ratio (circles) and $\phi_{\mathrm{P}}$ (triangles) during the high (HBP) and low biomass periods (LBP) and for the total time series (TTS), (b) Mantel $r$ ( \pm 1SE) relating changes in phytoplankton community composition to changes in 'TP MIX during the HBP, LBP and TTS, (c) 'expanding window' analysis of variance ratios and (d) 11-year 'moving window' analysis of variance ratios. In (c), the last year of the expanding window (first year always 1965) is shown on the $x$-axis. In (d), the midpoint of the moving window is shown on the $x$-axis. Vertical lines and shaded areas represent 95\% bootstrap confidence intervals. The vertical dashed line at VR 1 indicates independent dynamics. 
different community states during eutrophication and oligotrophica tion at $\mathrm{TP}_{\mathrm{MIX}}$ levels above $40 \mu \mathrm{g}$ TP $\mathrm{L}^{-1}$. The NMDS ordination clearly separated the most eutrophic from the most oligotrophic study periods, but suggests a similar community composition in both periods with mesotrophic conditions, i.e. the years 19651972 during eutrophication and the years 19841996 during oligotrophi cation (Fig. 4a). The reversal of community composition is also evi
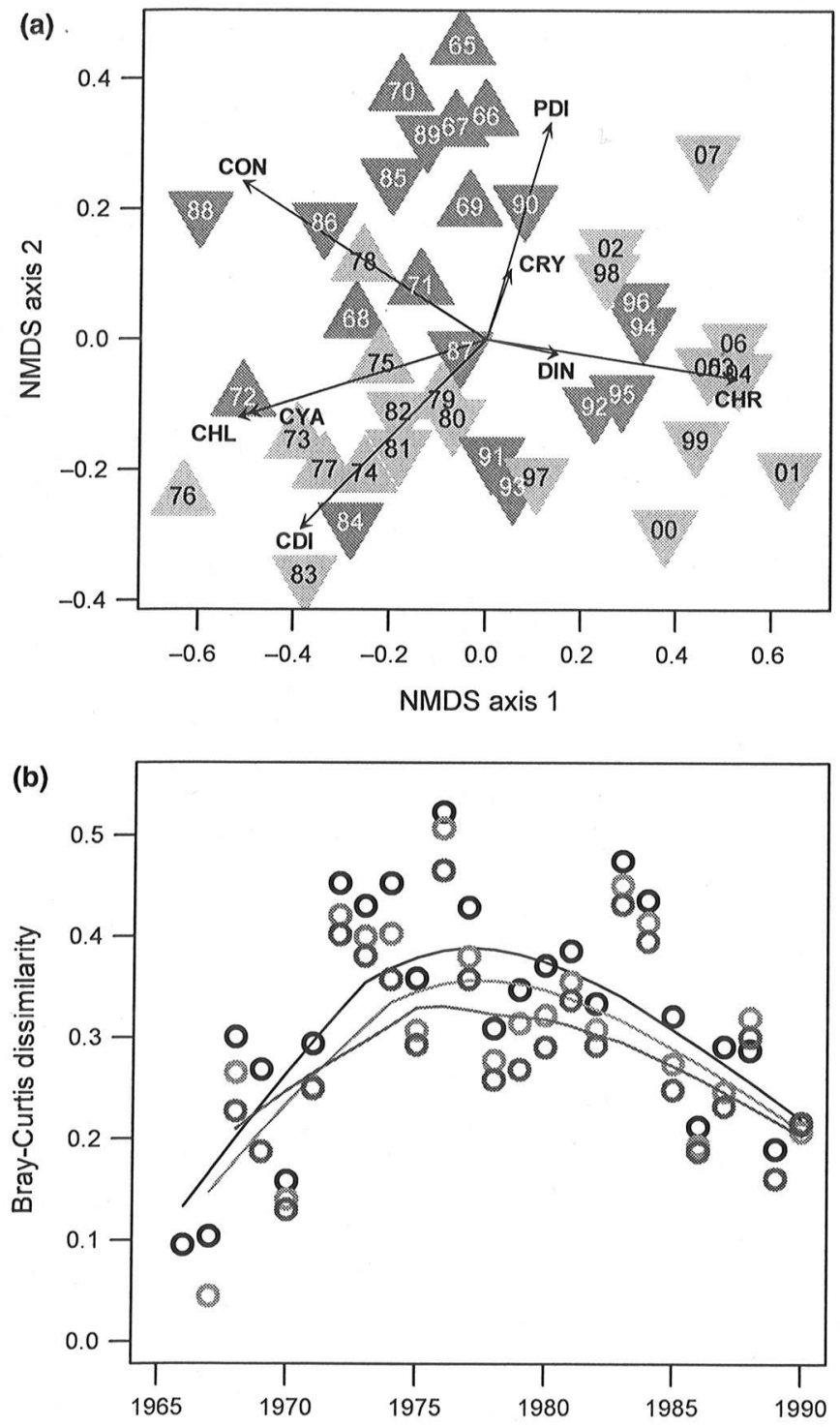

Figure 4 (a) NMDS ordination of study years based on Bray Curtis dissimilarities of phytoplankton groups (stress 0.135). Eutrophic years are shown as green, mesotrophic years as dark blue and oligotrophic years as light blue triangles. The years from 1965 to 1979 are shown as upward triangles (eutrophication years), the year from 1980 to 2007 as downward triangles (oligotrophication years). The arrows show the ordination of the different phytoplankton groups: for abbreviations see Fig. 1. (b) Bray Curtis dissimilarities of phytoplankton composition in the year shown on the $\mathrm{x}$ axis with the phytoplankton composition in 1965 (black), 1966 (red) and 1967 (blue). Lines represent loess fits. dent in the development of Bray Curtis dissimilarities of the first 3 years with the following years until 1990 (Fig. 4b). Dissimilarities to these first years strongly increased until peak eutrophication and then started to decrease again, resulting in a highly significant qua dratic relationship with time (all three adjusted $R^{2} \geq 0.3$, $P<0.01)$. As a consequence, dissimilarities of the years 19651967 with the year 1968 were very similar to those with the year 1990, as were $\mathrm{TP}_{\text {MIX }}$ values (1968: $36 \mu \mathrm{g} / \mathrm{L}, 1990: 39 \mu \mathrm{g} / \mathrm{L}$ ).

\section{DISCUSSION}

Using a four decade data set on phytoplankton dynamics, we show that a gradual change in nutrient availability of over one order of magnitude during eutrophication and subsequent oligotrophication was associated with a strong and fast decline of biomass within a few years. Such a rapid decline is a regime shift sensu Scheffer \& Carpenter (2003) and Andersen et al. (2009). To demonstrate bista bility, i.e. the existence of two locally stable stationary states in a dynamical system, a data set with several shifts between two different states would be necessary (Scheffer \& Carpenter 2003; Andersen et al. 2009). The sudden shift in phytoplankton biomass, i.e. the regime shift observed in Lake Constance separated two sta ble periods of annual average phytoplankton biomass, but is not sufficient evidence for bistability.

The regime shift occurred concurrently with the disappearance of both, biomass compensation, i.e. the adjustment of total biomass to environmental change, and compensatory dynamics between different phytoplankton groups. This might suggest that: (1) the maintenance of the community's capacity for biomass compensation and compensatory dynamics and (2) after a critical nutrient level was surpassed, the lack of compensation, and loss of compensatory dynamics, were key mechanisms leading to the phytoplankton bio mass regime shift in Lake Constance. During the high biomass state, $\mathrm{TP}_{\mathrm{MIX}}$ encompassed a range between 35 and $87 \mu \mathrm{g} \mathrm{L}^{-1}$ and shifted from mesotrophic to eutrophic conditions and back. During this time period, community change was strongly related to changes in $\mathrm{TP}_{\mathrm{MIX}}$, i.e. increases of some taxa with increasing nutrients were offset by decreases of other taxa resulting in a remarkable resilience of phytoplankton biomass. After the end of the period with signifi cant compensatory dynamics, biomass dropped to $47 \%$ within a few study years, although during this time $\mathrm{TP}_{\mathrm{MIX}}$ decrease did not accelerate. The magnitude of this regime shift is large compared to regime shifts observed in other large aquatic ecosystems. For exam ple, recent, presumably climate related, regime shifts in the equato rial Pacific and the North Sea were associated with a $36 \%$ decline in phytoplankton biomass in the former case (Chavez et al. 2003), and a $1321 \%$ increase in the latter case (McQuatters Gollop et al. 2007). Likewise, the invasion of Flathead Lake by opposum shrimp was suggested to have shifted primary productivity upward by $21 \%$ (Ellis et al. 2011). More data are needed to see whether there is a relationship between a community's capacity for compensation and the magnitude of the regime shift after an environmental threshold has been surpassed.

The shift in water temperatures observed in Lake Constance is also found in other aquatic habitats, e.g. lakes (Anneville et al. 2005), rivers (Hari et al. 2006), marine sites (Alheit et al. 2005) and even groundwater (Figura et al. 2011), and triggered by variability of the Arctic Oscillation (Figura et al. 2011). In Lake Constance, the regime shift of total phytoplankton biomass was statistically unre 
lated to this shift of water temperatures, but instead related to grad ual changes in $\mathrm{TP}_{\mathrm{MIX}}$. Furthermore, the observed patterns of phyto plankton biomass and composition are largely opposite to those expected from warming, as it is generally believed that warming will resemble and intensify effects of eutrophication on food webs (Moss et al. 2011) and result in e.g. higher biomasses of cyanobacte ria (Paerl \& Huisman 2008). More importantly, there is no convinc ing mechanistic explanation on why fast growing phytoplankton should decrease only with a delay of 2 years in response to increased water temperatures: (1) surface temperatures of Lake Con stance never exceeded $24{ }^{\circ} \mathrm{C}$, which suggests that the step wise increase of $0.7^{\circ} \mathrm{C}$ was unlikely to result in temperatures exceeding algal physiological optima, thereby reducing their growth rates, (2) Likewise, this increase will have only a small effect on zooplankton feeding rates and cannot overcompensate for the decline of herbi vores with oligotrophication (Appendix S5), (3) Warming did not result in a reduced length of the stratification period and (4) We also found no evidence for a role of enhanced stratification and subsequently reduced nutrient transport to the epilimnion for the phytoplankton decrease, e.g. substituting a measure of water column stability, the Schmidt stability, for WT in GAMs did not improve model performance related to models only considering $\mathrm{TP}_{\mathrm{MIX}}$ as an independent variable (statistical analyses not shown). Note that our results do not imply that warming has no influence on the plankton succession and the pelagic food web of Lake Constance, which is clearly not the case (e.g. Straile et al. 2010). However, this influence seems not to be detectable on the scale of interest in this study, i.e. annual averages of phytoplankton biomass within the upper $20 \mathrm{~m}$ of the water column. At this scale, biomass dynamics seem to be driven strongly by changes in the trophic status of the lake. This result, derived from the GAM models, is furthermore strongly con sistent with longitudinal and cross sectional field data (e.g. Watson et al. 1997; Jeppesen et al. 2005), as well as laboratory experiments (Sommer 1989) with respect to relative phytoplankton occurrence and performance patterns. To summarise, the decrease of phyto plankton biomass in Lake Constance is statistically unrelated to and

although we cannot fully exclude a role of temperature in, e.g. triggering the timing of the regime shift unlikely caused by the step wise increase of water temperatures in 1988 in this lake. Hence, our results support Scheffer \& Carpenter (2003) suggesting that fac tors slowly undermining resilience such as steady nutrient influx may be as important causes for regime shifts as more stochastic events like climate anomalies and/or species invasions. Similarly, regime shifts in other ecosystems should not be uncritically attrib uted to changes in climate even when there is an almost concurrent climatic shift, as in the case of Lake Constance.

Phytoplankton community dynamics clearly differed during both stable states. The HBP was characterised by compensatory dynamics among the phytoplankton taxa and year to year community dissimi larities were related to $\mathrm{TP}_{\mathrm{MIX}}$ differences. During the LBP, neither compensatory dynamics nor a relationship of community dynamics to $\mathrm{TP}_{\mathrm{MTX}}$ was observed (Fig. 3a,b).This is in accordance with recent results from grassland experiments where stronger compensatory dynamics were observed in fertilised communities (Grman et al. 2010). In contrast, in a microcosm experiment, phytoplankton spe cies showed higher compensatory capacity at low nutrient availabil ity (Zhang \& Zhang 2006). However, these results might be less relevant for functionally diverse natural phytoplankton communities, because only six chlorophyte species were used as a model commu nity. That said, our data and these experiments clearly show that the occurrence of compensatory dynamics is context dependent and that nutrient availability is an important factor regulating the type of interactions in algae and plant communities.

Our study also highlights the scale dependency of the relationship between compensatory dynamics and biomass compensation and also of the occurrence of compensatory dynamics. Compensatory dynam ics and biomass compensation are tightly related concepts, but their occurrence within a community is not necessarily linked, i.e. compen sation can occur in the presence or absence of compensatory dynam ics, and vice versa (Gonzalez \& Loreau 2009). In our case, this relationship changes depending on the length of the time series con sidered: During the HBP, compensation was associated with compen satory dynamics, during the LBP, compensation was associated with independent or even synchronous dynamics of phytoplankton groups, whereas when considering the whole time series, synchronous dynamics were associated with the lack of compensation, i.e. a regime shift. Thus, considering the complete study period, our results seem to support a recent review suggesting that compensatory dynamics are rare in nature (Houlahan et al. 2007). However, this conclusion based on the prevalence of positive covariances in community time series has been suggested to be premature (Gonzalez \& Loreau 2009) because positive covariances can be consistent with compensatory dynamics (Loreau \& Mazancourt 2008) and because scale resolving methods, i.e. methods that allow the simultaneous consideration of different time scales, may be necessary to detect compensatory dynamics (Vasseur et al. 2005). Our study demonstrates that the occurrence of compensatory dynamics depends also on the scale of environmental change. Changes in the type of community dynamics, i.e. a shift towards synchronous dynamics within a zooplankton com munity were also observed in response to acidification (Keitt 2008). In our study, only during a specific range of phosphorus concentra tions, some phytoplankton taxa were able to compensate for the decline of less tolerant taxa, whereas after a critical phosphorus threshold was passed, community dynamics became synchronous. Hence, during the high biomass state, strong compensatory dynamics of phytoplankton in response to gradual environmental change existed. Indeed, strong 'out break' compensatory dynamics are pre dicted to occur when there are high levels of autocorrelation in the environment (Gonzalez \& Loreau 2009). Under these circumstances, the detection of compensatory dynamics seems to be possible even without the use of scale resolving methods.

The loss of compensatory dynamics with oligotrophication may be caused by a change in the dominance pattern of factors limiting phytoplankton growth occurring during the transition from the high biomass towards the low biomass state. Large phytoplankton blooms in the HBP led to strong depletion of silicate and $\mathrm{CO}_{2}$ and increased light attenuation within the water column (Appendix S5). In the LBP, phosphorus concentrations were strongly limiting throughout most of the season (Anneville et al. 2005), and low phytoplankton abundances were less able to reduce the availability of silicate, carbon and light (Appendix S5). Simultaneously, daphnids declined during oligotrophication in Lake Constance (Stich \& Brinker 2010) indicating that also grazing losses decreased (Appendix S5). Consequently, the system shifted from a multifacto rial control during the HBP (Sommer 1987), in which the control ling factor probably differed between phytoplankton groups (see below), to a strong bottom up control dominated by phosphorus limitation for most phytoplankton groups. 
Despite the loss of compensatory dynamics, total phytoplankton biomass was also rather stable in the low biomass period. The resil ience of phytoplankton to further track the threefold decline of $\mathrm{TP}_{\mathrm{MIX}}$ after the mid 1990s might possibly be the result of reduced daphnid grazing, which declined threefold from the early 1990s towards 2007 (Stich \& Brinker 2010), i.e. a decline exceeding that of phytoplankton biomass. As a consequence, the Daphnia abun dance/phytoplankton biomass ratio decreased (Appendix S5). This might suggest that the main factor contributing to overall phyto plankton biomass resilience shifted from algal algal interactions dur ing the high biomass state to algal zooplankton interactions in the low biomass state. This pattern is partially consistent with food chain theory, which predicts a shift in the importance of bottom up to top down control in structuring communities with changing eco system productivity (Oksanen et al. 1981).

Our results also have important implications for the management of lake ecosystems. When considering the range from ultra oligo trophic to hypereutrophic trophic states, the relationship between phosphorus concentrations and phytoplankton biomass (Watson et al. 1992), or phosphorus concentrations and chlorophyll (Mc Cauley et al. 1989) among lakes has been shown to follow a sig moid form with nitrogen limitation resulting in a plateau of the phosphorous biomass relationship at TP levels exceeding approxi mately $1000 \mu \mathrm{g} \mathrm{L}^{-1}$. Our study is the first demonstrating such a sigmoid relationship for an individual lake. However, in Lake Con stance, the plateau, or carrying capacity with respect to phosphorus is not due to nitrogen limitation (Sommer 1987), but rather due to a multitude of limiting factors (see above, Appendix S5, Sommer 1987), which most likely affect the various phytoplankton groups differently and thereby induce a variety of individual responses of the algal taxa leading to the observed compensatory dynamics. For example, high phytoplankton biomasses during periods of high phosphorus loading can result in silicate limitation for diatoms (Huber et al. 2008), $\mathrm{CO}_{2}$ limitation especially for chrysophytes (Maberly et al. 2009), or light limitation, which might first affect chlorophytes, cryptophytes and dinophytes (Schwaderer et al. 2011). Clearly, detailed analyses of the relationships between phytoplank ton groups and other potential drivers are logical next steps to pur sue; such detailed analyses are, however, beyond the scope of this study. Nevertheless, our results indicate that the observed sigmoid phosphorus phytoplankton relationship across lakes (McCauley et al. 1989) covering several orders of magnitude of phosphorus and biomass values might be actually composed by a multitude of lake specific sigmoid phosphorus phytoplankton relationships each covering a smaller individual range of phosphorus and bio mass values.

Total phytoplankton biomass, the biomass of most taxonomic groups as well as community composition showed a similar response to $\mathrm{TP}_{\mathrm{MIX}}$ variability independently, whether $\mathrm{TP}_{\mathrm{MIX}}$ was increasing or decreasing (see trajectories in Figs 2 and 4b, Appendix S2), i.e. there was no strong evidence for hysteresis (Scheffer \& Carpenter 2003). Currently, it is unclear to what extent the reversibility of phytoplankton trajectories in Lake Constance is also present at a) a higher taxonomic resolution, e.g. at species level and b) for an extended range of $\mathrm{TP}_{\mathrm{MIX}}$ values. Diatom species lists from sedimentary records which extend also to time periods prior to the 1960 s, i.e. to the pre eutrophication period, show that at least some species (e.g. Acbnanthes minutissima, Cyclotella cyclopuncta, Tabellaria fenestrata) which disappeared during eutrophication eventually reappeared in the course of oligotrophi cation (Kümmerlin 1998). Reversibility of trajectories after a fast recovery from high levels of diffusive nutrient inflow has also been shown for a diatom community in an Irish lake (Donohue et al. 2010). Likewise, zooplankton response to fish additions revealed reversibility and smooth transitions between community states (Mittelbach et al. 2006). This suggests that community changes that were caused by environmental change might at least partly be reversible also at the species level. On the other hand, microevolutionary adaptation might result into irreversible changes in populations as has been suggested for the cladoceran Daphnia in Lake Constance (Brede et al. 2009). However, for a diatom species in a Danish fjord, no changes in genetic structure with eutrophication were found (Härnström et al. 2011). Hence, it is presently not clear whether and to which extent microevolutionary changes will prevent the reversibility of phytoplankton trajectories. Nevertheless, the results presented in our study seem to be in contrast to the results of Duarte et al. (2009), which suggest that phytoplankton trajectories in coastal seas should be characterised as non reversible due to regime shifts and shifting baselines. Rather, the Lake Constance phytoplankton data suggest reversibil ity despite the occurrence of a regime shift and a shift in baseline temperatures. However, the conclusion of Duarte et al. (2009) was not based on statistical analyses but primarily on visual examina tion of phytoplankton trajectories in four case studies. In deep lakes, the lagged response of phytoplankton biomass during phos phorus decline has also been regarded as evidence for hysteresis (Dokulil \& Teubner 2005). However, in almost all deep lakes, high quality data cover mostly the period of oligotrophication, whereas only sparse data document the process of eutrophication. Hence, in most other studies, analyses whether and to which extent the biomass response to oligotrophication really differed from that to eutrophication in deep lakes was not possible. Clearly, there is a need for more data to allow for a robust evalu ation regarding the reversibility of phytoplankton trajectories as a consequence of nutrient reduction efforts in these lakes and in other aquatic systems. Likewise, it should be acknowledged that our conclusions should be viewed keeping in mind the general limitations of observational studies. Hence, there is an urgent need to test experimentally whether specific types of community interactions or changes in the type of community interactions may prevent, delay or cause regime shifts.

\section{CONCLUSIONS}

Using a unique data set of phytoplankton dynamics covering four decades, we show that compensatory dynamics maintained stable phytoplankton biomasses over a large gradient of phosphorus con centrations. Presumably, only after phosphorus concentrations fell below a critical threshold, compensatory dynamics within the phyto plankton community ceased and consequently biomass dropped to a lower level within a few years. The Lake Constance case study shows that the trajectories of eutrophication can be reversed suc cessfully in deep lakes. However, to reduce phytoplankton biomass, restoration measures needed to overcome the compensatory capac ity of the phytoplankton community. Long term changes in the phytoplankton community of Lake Constance hence provide an example showing that continuous environmental change can affect the compensatory capacity of a natural community. 


\section{ACKNOWLEDGEMENTS}

We thank the Internationale Gewässerschutzkommission für den Bodensee (IGKB) for providing the long term data, and Karl Otto Rothhaupt, Ursula Gaedke, Robert Ptacnik and Ulrich Sommer for discussions and comments on a previous version of the manuscript. We thank Roxana Halbleib for statistical advice and three anony mous referees for insightful comments. Funding was provided by the LUBW, Landesanstalt für Umwelt, Messungen und Naturschutz Baden Württemberg.

\section{AUTHORSHIP}

MCJ analysed the data. MCJ and DS wrote the first draft of the manuscript. RK provided the long term data and contributed sub stantially to revisions of the manuscript.

\section{REFERENCES}

Alheit, J., Mollmann, C., Dutz, J., Kornilovs, G., Loewe, P., Mohrholz, V. et al. (2005). Synchronous ecological regime shifts in the central Baltic and the North Sea in the late 1980s. ICES J. Mar: Sci., 62, 12051215.

Andersen, T., Carstensen, J., Hernandez-Garcia, E. \& Duarte, C.M. (2009). Ecological thresholds and regime shifts: approaches to identification. Trends Ecol. Evol., 24, 4957.

Anneville, O., Gammeter, S. \& Straile, D. (2005). Phosphorus decrease and climate variability: mediators of synchrony in phytoplankton changes among European peri-alpine lakes. Freshw. Biol., 50, 17311745.

Bai, Y.F., Han, X.G., Wu, J.G., Chen, Z.Z. \& Li, L.H. (2004). Ecosystem stability and compensatory effects in the Inner Mongolia grassland. Nature, 431, 181184.

Brede, N., Sandrock, C., Straile, D., Spaak, P., Jankowski, T., Streit, B. et al. (2009). The impact of human-made ecological changes on the genetic architecture of Daphnia species. Proc. Natl Acad. Sci. USA, 106, 4758 4763.

Carpenter, S.R. (2005). Eutrophication of aquatic ecosystems: Bistability and soil phosphorus. Proc. Natl Acad. Sci. USA, 102, 1000210005.

Chavez, F.P., Ryan, J., Lluch-Cota, S.E. \& Niquen, M. (2003). From anchovies to sardines and back: Multidecadal change in the Pacific Ocean. Science, 299, 217221.

Dokulil, M.T. \& Teubner, K. (2005). Do phytoplankton communities correctly track trophic changes? An assessment using directly measured and palaeolimnological data. Freshw. Biol, 50, 15941604.

Donohue, I., Leira, M., Hobbs, W., Leon-Vintro, L., O’Reilly, J. \& Irvine, K. (2010). Rapid ecosystem recovery from diffuse pollution after the Great Irish Famine. Ecol. Appl., 20, 17331743.

Duarte, C.M., Conley, D.J., Carstensen, J. \& Sanchez-Camacho, M. (2009). Return to Neverland: Shifting Baselines Affect Eutrophication Restoration Targets. Estuaries Coasts, 32, 2936.

Ellis, B.K., Stanford, J.A., Goodman, D., Stafford, C.P., Gustafson, D.L., Beauchamp, D.A. et al. (2011). Long-term effects of a trophic cascade in a large lake ecosystem. Proc. Natl Acad. Sci. USA, 108, 10701075.

Elmqvist, T., Folke, C., Nystrom, M., Peterson, G., Bengtsson, J., Walker, B. et al. (2003). Response diversity, ecosystem change, and resilience. Front. Ecol. Environ., 1, 488494.

Figura, S., Livingstone, D.M., Hoehn, E. \& Kipfer, R. (2011). Regime shift in groundwater temperature triggered by the Arctic Oscillation. Geophys. Res. Lett., 38, L23401. DOI:10.1029/2011GL049749.

Fischer, J.M., Frost, T.M. \& Ives, A.R. (2001). Compensatory dynamics in zooplankton community responses to acidification: Measurement and mechanisms. Ecol. Appl., 11, 10601072.

Gonzalez, A. \& Loreau, M. (2009). The Causes and Consequences of Compensatory Dynamics in Ecological Communities. Annu. Rev. Ecol. Evol. Syst., 40, 393414.
Grman, E., Lau, J.A., Schoolmaster, D.R. \& Gross, K.L. (2010). Mechanisms contributing to stability in ecosystem function depend on the environmental context. Ecol. Lett., 13, 14001410.

Hari, R.E., Livingstone, D.M., Siber, R., Burkhardt-Holm, P. \& Güttinger, H (2006). Consequences of climatic change for water temperature and brown trout populations in Alpine rivers and streams. Glob. Change Biol., 12, 1026.

Härnström, K., Ellegaard, M., Andersen, T.J. \& Godhe, A. (2011). Hundred years of genetic structure in a sediment revived diatom population. Proc. Nat Acad. Sci. USA, 108, 42524257.

Houlahan, J.E., Currie, D.J., Cottenie, K., Cumming, G.S., Ernest, S.K.M., Findlay, C.S. et al. (2007). Compensatory dynamics are rare in natural ecological communities. Proc. Natl Acad. Sci. USA, 104, 32733277.

Huber, V., Adrian, R. \& Gerten, D. (2008). Phytoplankton response to climate warming modified by trophic state. Limnol. Oceanogr., 53, 113.

Jackson, J.B.C., Kirby, M.X., Berger, W.H., Bjorndal, K.A., Botsford, L.W., Bourque, B.J. et al. (2001). Historical overfishing and the recent collapse of coastal ecosystems. Science, 293, 629638.

Jeppesen, E., Sondergaard, M., Jensen, J.P., Havens, K.E., Anneville, O., Carvalho, L. et al. (2005). Lake responses to reduced nutrient loading - an analysis of contemporary data from 35 European and North American long term studies. Freshw. Biol, 50, 17471771.

Keitt, T.H. (2008). Coherent ecological dynamics induced by large-scale disturbance. Nature, 454, 331 U39.

Kümmerlin, R.E. (1998). Taxonomical response of the phytoplankton community to Upper Lake Constance (Bodensee-Obersee) to eutrohication and reoligotrophication. Arch. Hydrobiol. Spec. Issues Advanc. Limnol., 53, 109117.

Litchman, E., Klausmeier, C.A., Schofield, O.M. \& Falkowski, P.G. (2007). The role of functional traits and trade-offs in structuring phytoplankton communities: scaling from cellular to ecosystem level. Ecol. Lett., 10, 11701181.

Loreau, M. \& de Mazancourt, C. (2008). Species synchrony and its drivers: Neutral and nonneutral community dynamics in fluctuating environments. $A \mathrm{~m}$. Nat., 172, E48 E66.

Maberly, S.C., Ball, L.A., Raven, J.A. \& Sultemeyer, D. (2009). Inorganic Carbon Acquisition by Chrysophytes. J. Phycol., 45, 10521061.

McCauley, E., Downing, J.A. \& Watson, S. (1989). Sigmoid Relationships Between Nutrients and Chlorophyll Among Lakes. Can. J. Fish. Aquat. Sci., 46, 11711175 .

McQuatters-Gollop, A., Raitsos, D.E., Edwards, M., Pradhan, Y., Mee, L.D., Lavender, S.J. et al. (2007). A long-term chlorophyll data set reveals regime shift in North Sea phytoplankton biomass unconnected to nutrient trends. Limnol. Oceanogr., 52, 635648.

Mittelbach, G.G., Garcia, E.A. \& Taniguchi, Y. (2006). Fish reintroductions reveal smooth transitions between lake community states. Ecology, 87, 312 318.

Moss, B., Kosten, S., Meerhoff, M., Battarbee, R.W., Jeppesen, E., Mazzeo, N. et al. (2011). Allied attack: climate change and eutrophication. Inland waters, 1, 101105.

Oksanen, L., Fretwell, S.D., Arruda, J. \& Niemelä, P. (1981). Exploitation ecosystems in gradients of primary productivity. Am. Nat., 118, 240261.

Paerl, H.W. \& Huisman, J. (2008). Climate - Blooms like it hot. Science, 320, 57 58.

Rodionov, S.N. (2004). A sequential algorithm for testing climate regime shifts. Geophys. Res. Lett., 31, Art. No. L09204. DOI: 10.1029/2004 GL019448.

Scheffer, M. \& Carpenter, S.R. (2003). Catastrophic regime shifts in ecosystems: linking theory to observation. Trends Ecol. Evol., 18, 648656.

Scheffer, M., Carpenter, S., Foley, C. \& Walker, B. (2001). Catastrophic shifts in ecosystems. Nature, 413, 591596.

Schindler, D.E., Hilborn, R., Chasco, B., Boatright, C.P., Quinn, T.P., Rogers, L. A. et al. (2010). Population diversity and the portfolio effect in an exploited species. Nature, 465, 609 U102.

Schluter, D. (1984). A Variance Test for Detecting Species Associations, with Some Example Applications. Ecology, 65, 9981005

Schwaderer, A.S., Yoshiyama, K., De Tezanos Pinto, P., Swenson, N.G., Klausmeier, C.A. \& Litchman, E. (2011). Eco-evolutionary differences in light utilization traits and distributions of freshwater phytoplankton. Limnol. Oceanogr, 56, 589598. 
Smith, V.H. \& Schindler, D.W. (2009). Eutrophication science: where do we go from here? Trends Ecol. Evol, 24, 201207.

Sommer, U. (1987). Factors controlling the seasonal variation in phytoplankton species composition - A case study for a deep, nutrient rich lake. Prog. Phycol. Res., 5, 123179.

Sommer, U. (1989). The role of competition for resources in phytoplankton succession. In Plankton Ecology: Succession in Plankton Communities. (ed Sommer, U.). Springer, Berlin, pp. 57106.

Stich, H.B. \& Brinker, A. (2010). Oligotrophication outweighs effects of global warming in a large, deep, stratified lake ecosystem. Glob. Change Biol., 16, 877 888.

Straile, D., Kerimoglu, O., Peeters, F., Jochimsen, M.C., Kümmmerlin, R., Rinke, K. et al. (2010). Effects of a half a millennium winter on a deep lake - a shape of things to come? Glob. Change Biol., 16, 28442856

Vasseur, D.A., Gaedke, U. \& McCann, K.S. (2005). A seasonal alternation of coherent and compensatory dynamics occurs in phytoplankton. Oikes, 110 507514

Vitousek, P.M., Aber, J.D., Howarth, R.W., Likens, G.E., Matson, P.A., Schindler, D.W. et al. (1997). Human alternation of the global nitrogen cycle: sources and consequences. Ecol. Appl., 7, 737750.

Watson, S., McCauley, E. \& Downing, J.A. (1992). Sigmoid Relationships Between Phosphorus, Algal Biomass, and Algal Community Structure. Can. J. Fish. Aquat. Sci., 49, 26052610.

Watson, S.B., McCauley, E. \& Downing, J.A. (1997). Patterns in phytoplankton taxonomic composition across temperate lakes of differing nutrient status. Limnol. Oceanogr., 42, 487495.
Wood, S.N. (2006). Generalized Additive Models: An Introduction with R. Chapman \& Hall/CRC, Boca Raton.

Zhang, Q.G. \& Zhang, D.Y. (2006). Resource availability and biodiversity effects on the productivity, temporal variability and resistance of experimental algal communities. Oikos, 114, 385396.

\section{SUPPORTING INFORMATION}

Additional Supporting Information may be downloaded via the online version of this article at Wiley Online Library (www.ecologyletters.com)

As a service to our authors and readers, this journal provides sup porting information supplied by the authors. Such materials are peer reviewed and may be re organised for online delivery, but are not copy edited or typeset. Technical support issues arising from supporting information (other than missing files) should be addressed to the authors. 


\title{
Compensatory dynamics and the stability of phytoplankton biomass during 4 decades of eutrophication and oligotrophication
}

\author{
Marc Jochimsen $^{1}$, Reiner Kümmerlin ${ }^{2} \&$ Dietmar Straile $^{1}$ \\ 1 Limnological Institute, University of Konstanz, 78464 Konstanz, , Germany \\ 2 Institut für Seenforschung, 88085 Langenargen, Germany
}

\section{Appendix A1 Detailed description of material and methods}

Sampling of phytoplankton and abiotic parameters - Phytoplankton was sampled from 1965 to 2007 at the centre of Upper Lake Constance. During these 43 years a total number of 1040 phytoplankton samples was taken, which corresponds on average to an approximately half-monthly sampling regime. The seasonal resolution of sampling was higher in the first 4 study years (30-48 samplings per year) and lower in 1972, 1974 and 1975 (13-15 samplings per year). From 1965 - 1975 the phytoplankton sampling procedure comprised discrete depths sampling of the $0-50 \mathrm{~m}$ water column with a Ruttner sampler, thereafter the $0-20 \mathrm{~m}$ water column was sampled with an integrated Schröder sampler. A depth of $20 \mathrm{~m}$ is considered as the maximal vertical extent of the euphotic zone in Lake Constance during eutrophic and mesotrophic years (Tilzer \& Beese 1988). To achieve comparability between both sampling methods, biomass estimates until 1975 were adjusted by assuming that phytoplankton was evenly distributed throughout the water column when the water column was fully mixed, but concentrated in the upper mixed layer during the stratified season. We assume that the water column within the upper $50 \mathrm{~m}$ is fully mixed if gradients along water temperature profiles did not exceed $1{ }^{\circ} \mathrm{C} \mathrm{m}^{-1}$. The extension of the upper mixed layer was estimated from water temperature profiles as the minimum depth $\left(\mathrm{z}_{\min }\right)$ at which a gradient exceeding $1^{\circ} \mathrm{C} \mathrm{m}^{-1}$ occurs. If $z_{\min }<20 \mathrm{~m}$ all phytoplankton is assumed to be concentrated in the upper $20 \mathrm{~m}$ of the water column, i.e. the water column sampled after 1975. Hence, phytoplankton biomass 
estimates prior to 1976 were adjusted according to $\mathrm{B}_{\mathrm{adj}}=\mathrm{B}_{0-50} * 50 / \mathrm{z}_{\min }$, with $\mathrm{z}_{\min }$ varying between 20 and 50 .

After fixation in Lugol's iodine solution phytoplankton cells were enumerated using inverted microscopy (Utermöhl 1958) and taxonomically resolved mostly to species or, where not possible, to a higher taxonomic level. For the most part of the study period (1984-2007), one of us (RK) was responsible for counting and identification of the species which ensured the comparability of the data. Abundance estimates were converted to fresh mass based on measurements of species-specific cell volumes, using a specific weight factor of $1.03 \mathrm{~g} / \mathrm{cm}^{3}$ (Hillebrand et al. 1999). The response of phytoplankton to changing nutrient concentrations varies seasonally and is expected to be stronger in e.g., summer as compared to spring (Anneville et al. 2005;Gaedke 1998). Oligotrophication results in an increase of the seasonal window of limiting phosphorus concentrations from only a short period during summer in eutrophic years towards a longer period encompassing summer and spring during oligotrophic years (Anneville et al. 2005). In order to adequately consider also this seasonal increase of the phosphorus limitation window on phytoplankton biomass, we focus our analyses on annual averages of biomasses and not on e.g. summer averages. In order to achieve a homogenous and seasonally balanced data set for the calculation of annual biomass averages, the latter were calculated from a data set linearly interpolated to a evenly spaced matrix of 26 data points per year.

Chemical variables and water temperatures were measured monthly or biweekly (since 1995) at water column depths of $0,5,10,15,20,30,50,100,200$, and $250 \mathrm{~m}$ using standard methods (Rossknecht 1998). Zooplankton samples were collected with net hauls (mesh size $100 \mu \mathrm{m}$ ) from $100 \mathrm{~m}$ depth (Seebens et al. 2007). 
Statistical methods - Significance of the water temperature trend was assessed using the trend-free pre-whitening procedure (Yue et al. 2002). As a test for the occurrence of a phytoplankton biomass regime shift we used Rodionov's regimes shift detection method (RRSD, Rodionov 2004). Results of the test were robust against reasonable choices of the model parameters, i.e., the minimum regime length (5 - 25 years) and the Huber weight parameter $(0.5-1)$. In addition, we fitted the long-term development of total phytoplankton biomass and water temperatures with a modified logistic function,

$$
Y_{t}=a+b \frac{e^{T-t}}{1+e^{T-t}},
$$

which connects two periods of stable state variables by a transitional period: $Y_{t}$ is total phytoplankton biomass, respectively WT in year $\mathrm{t}$, a and b determine the biomasses, respectively WT at the two stable periods, and T denotes the inflection year, i.e., the year with the largest change in $Y_{t}$.

The relationship between phytoplankton groups and potential environmental drivers TP $_{\mathrm{MIX}}$ and WT) was analysed using generalized additive models (GAMs) with Gaussian errors and restricted maximum likelihood (REML) as smoothness selection method using the mgcv package within R (Wood 2006). Phytoplankton biomasses and TP $\mathrm{MIX}_{\mathrm{X}}$ were log-transformed to achieve normality and variance homogeneity and to allow for a better comparison with published phytoplankton biomass - phosphorus relationships (Watson et al. 1992). GAMs fit smoothing functions of the independent variables and hence permit nonlinear relationship between dependent and independent parameters. The estimated degrees of freedom (e.d.f.) indicate the degree of non-linearity of the GAMs, e.d.f. close to 1 imply linear relationships and e.d.f. $>1$ progressively higher-order relationships. e.d.f. close to zero indicate that the estimated smooths for a specific independent variable have been virtually removed from the model. In such cases (when e.d.f. $<0.5$ ) no $\mathrm{p}$ - values are reported by the mgcv package because distributional approximations of $p$ - values break down (Wood 2006). When smooths 
of an independent variable were non-significant or their e.d.f. were close to 0 , we refitted the model without them in order to verify that the smooths of the parameters remaining in the models have not changed and model deviances have not strongly increased.

To analyse whether phytoplankton groups displayed compensatory, independent or synchronous dynamics, we calculated two related community metrics, VR (Schluter 1984) and $\varphi_{\mathrm{P}}$ (Loreau \& de Mazancourt 2008). Both metrics relate the variance of the community biomass $(\mathrm{C})$ to the variances of the biomasses of individual taxa $\left(\mathrm{P}_{\mathrm{i}}\right)$ within the community:

$$
\begin{aligned}
& V R=\frac{\operatorname{var}(C)}{\sum \operatorname{var}\left(P_{i}\right)} \\
& \varphi_{P}=\frac{\operatorname{var}(C)}{\left(\sum \sqrt{\operatorname{var}\left(P_{i}\right.}\right)^{2}}
\end{aligned}
$$

As $\operatorname{var}(C)=\sum \operatorname{var}\left(P_{i}\right)+2 \sum \sum \operatorname{cov}\left(P_{i}, P_{j}\right)$, a VR of 1 occurs when taxa fluctuate independently or when positive and negative covariances between species neutralise each other exactly (Gonzalez \& Loreau 2009). A VR > 1 indicates that the sum of co-variances among taxa is positive (synchronous dynamics), whereas a VR $<1$ (compensatory dynamics) occurs when the sum of covariances is negative. In contrast, $\varphi_{\mathrm{P}}$ is standardized between 0 and 1 denoting perfect compensatory and perfect synchronous dynamics, respectively. Using $\varphi_{\mathrm{P}}$ it is possible to directly compare communities differing in the number of taxa considered. It additionally makes no specific assumption about the magnitude and distribution of biomasses and variances (Loreau \& de Mazancourt 2008). Both community metrics were calculated for distinct periods within the time series (HBP, LBP, TTS). In addition, we performed an 11year 'moving window' analysis and an 'expanding window' analysis. For the latter, we first calculated both community metrics for the time period from 1965-1975. Then the calculation window was continuously expanded by one additional study year until the full time series was included. $95 \%$ confidence intervals of VR and $\varphi_{P}$ were calculated with time series 
bootstrapping using the R package boot (Canty \& Riley 2010). To account for the autocorrelation structure of the time series we used bootstrapping through block resampling (Davison \& Hinkley 1997) with a mean geometric block length of 5 years. Estimated confidence intervals were robust in respect to changes in block length.

In order to study the overall community trajectories, we calculated Bray-Curtis community composition dissimilarities between the study years, which were used as a basis for NMDS ordination and to test for relationships between community dissimilarity and the ratio of $\mathrm{TP}_{\mathrm{MIX}}$ values between years (Mantel test). Data analysis was performed using the software packages SAS for Windows 9.12 (SAS Institute 1988) and R for Windows 2.9.1 (R Development Core Team 2005).

\section{References}

Anneville O., Gammeter S. \& Straile D. (2005) Phosphorus decrease and climate variability: mediators of synchrony in phytoplankton changes among European peri-alpine lakes. Freshwater Biology 50, 1731-1745

Canty A. \& Ripley B. (2010) boot: Bootstrap R (S-Plus) functions. R package 1.2-43.

Davison A.C. \& Hinkley D.V. (1997) Bootstrap methods and their applications. Cambridge University Press, Cambridge.

Gaedke U. (1998) Functional and taxonomical properties of the phytoplankton community of large and deep Lake Constance: interannual variability and response to re-oligotrophication (1979-1993). Arch.Hydrobiol.Spec.Issues Advanc.Limnol. 53, 119-141

Gonzalez A. \& Loreau M. (2009) The Causes and Consequences of Compensatory Dynamics in Ecological Communities. Annual Review of Ecology Evolution and Systematics 40, 393 414

Hillebrand H., Durselen C.D., Kirschtel D., Pollingher U. \& Zohary T. (1999) Biovolume calculation for pelagic and benthic microalgae. Journal of Phycology 35, 403-424

Loreau M. \& de Mazancourt C. (2008) Species synchrony and its drivers: Neutral and nonneutral community dynamics in fluctuating environments. American Naturalist 172, E48E66

R Development Core Team (2005) R: A language and environment for statistical computing. $R$ Foundation for Statistical Computing, Vienna, Austria.ISBN 3-900051-07-0 URL:

http://www.R-project.org. 
Rodionov S.N. (2004) A sequential algorithm for testing climate regime shifts. Geophysical Research Letters 31, Art. No. L09204, DOI: 10.1029/2004GL019448

Rossknecht H. (1998) Langjährige Entwicklung chemischer Parameter im Bodensee-Obersee. Ber.Int.Gewässerschutzkomm.Bodensee 48, 1-137

SAS Institute (1988) SAS/STAT user's guide, release 6.03 edition. SAS Institute, Cary, North Carolina, USA.

Schluter D. (1984) A Variance Test for Detecting Species Associations, with Some Example Applications. Ecology 65, 998-1005

Seebens H., Straile D., Hoegg R., Stich H.B. \& Einsle U. (2007) Population dynamics of a freshwater calanoid copepod: complex responses to changes in trophic status and climate variability. Limnology and Oceanography 52, 2364-2372

Tilzer M.M. \& Beese B. (1988) The seasonal productivity cycle of phytoplankton and controlling factors in Lake Constance. Schweiz.Z.Hydrol. 50, 1-39

Utermöhl H. (1958) Zur Vervollkommnung der quantitativen Phytoplankton-Methodik. Mitt.Internat.Verein.Limnol. 9, 1-38

Watson S., McCauley E. \& Downing J.A. (1992) Sigmoid Relationships Between Phosphorus, Algal Biomass, and Algal Community Structure. Canadian Journal of Fisheries and Aquatic Sciences 49, 2605-2610

Wood S.N. (2006) Generalized Additive Models: An Introduction with R. Chapman \& Hall/CRC, Boca Raton.

Yue S., Pilon P., Phinney B. \& Cavadias G. (2002) The influence of autocorrelation on the ability to detect trend in hydrological series. Hydrological Processes 16, 1807-1829 


\section{Compensatory dynamics and the stability of phytoplankton biomass during 4 decades of eutrophication and oligotrophication}

Marc Jochimsen $^{1}$, Reiner Kümmerlin² \& Dietmar Straile ${ }^{1}$

1 Limnological Institute, University of Konstanz, 78464 Konstanz, , Germany

2 Institut für Seenforschung, 88085 Langenargen, Germany

Appendix S2 The relationship between annual average biomasses of phytoplankton groups and TP $\mathbf{M I X}_{\mathrm{X}}$
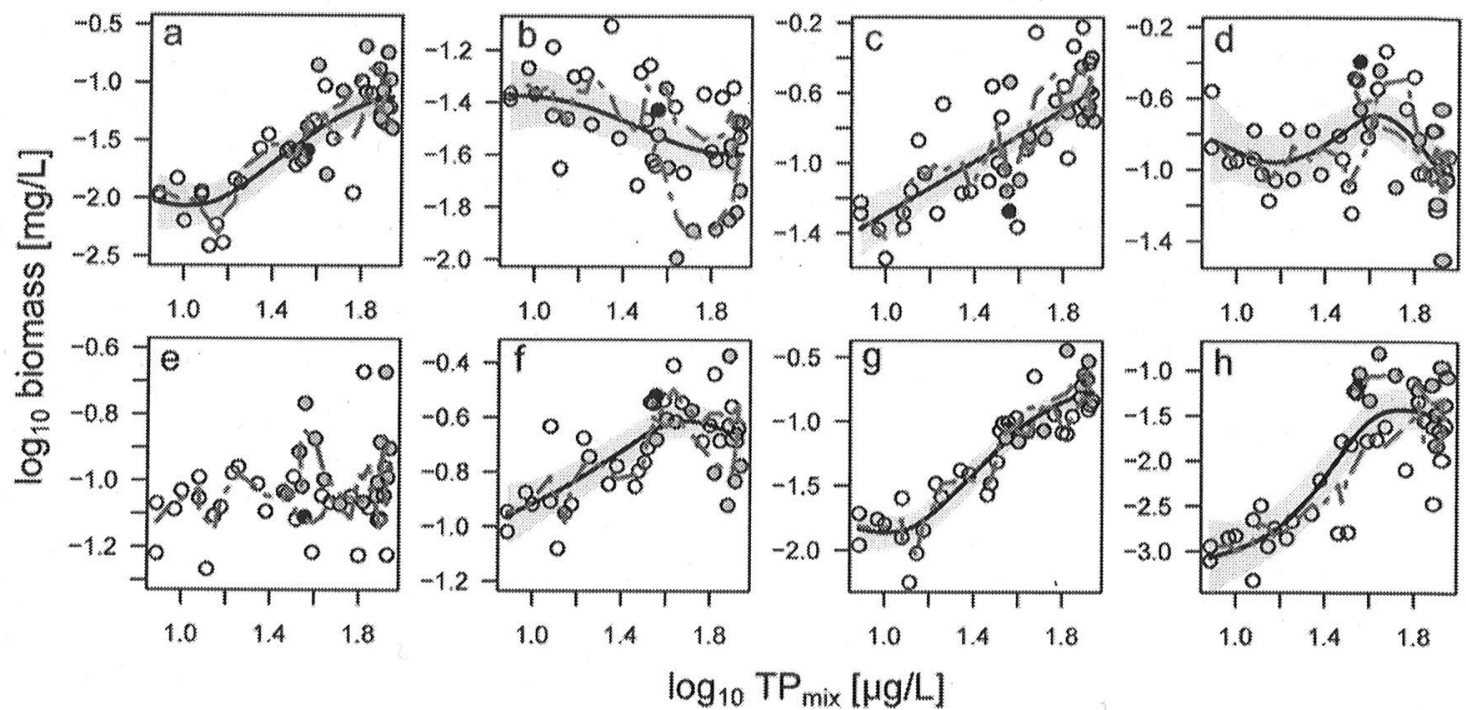

Fig. S2-1 Relationships between $\log _{10}$ transformed total phosphorus concentrations and log-transformed biomasses of a) cyanophytes (CYA), b) chrysophytes (CHR), c) centric diatoms (CDI), d) pennate diatoms (PDI), e) dinophytes (DIN), f) cryptophytes (CRY), g) chlorophytes (CHL) and h) Conjugales (CON). The solid lines present the significant smooths ( $\pm 2 \mathrm{SE}$, grey areas) of the generalized additive models with $\mathrm{TP}_{\mathrm{MIX}}$ as independent variable (see Table 1). The dashed grey lines indicate the temporal trajectories based on a three year moving average. The black dots represent the start of the study period (1965), the grey dots the years of eutrophication, and the white dots the subsequent years of oligotrophication. 


\title{
Compensatory dynamics and the stability of phytoplankton biomass during 4 decades of eutrophication and oligotrophication
}

\author{
Marc Jochimsen $^{1}$, Reiner Kümmerlin ${ }^{2}$ \& Dietmar Straile ${ }^{1}$ \\ 1 Limnological Institute, University of Konstanz, 78464 Konstanz, , Germany \\ 2 Institut für Seenforschung, 88085 Langenargen, Germany
}

\begin{abstract}
Appendix S3 Results of statistical analyses relating phytoplankton biomasses lagged by

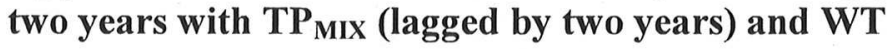

Table 1. Summary of GAMs relating phytoplankton biomasses of total phytoplankton lagged by two years (TOTAL) and of the different phytoplankton groups to $\mathrm{TP}_{\mathrm{MIX}}$ (lagged by 2 years) and WT (full model) and to TP $\mathrm{PIX}_{\mathrm{X}}$ and WT separately. Abbreviations used for phytoplankton groups are: cyanophytes (CYA), chrysophytes (CHR), centric diatoms (CDI), pennate diatoms (PDI), dinophytes (DIN), cryptophytes (CRY), chlorophytes (CHL) and Conjugales $(\mathrm{CON})$. For all variables in the models the estimated degree of freedom (e.d.f) and $\mathrm{F}$ values with corresponding significance levels $(* * * \mathrm{P}<0.001, * * \mathrm{P}<0.01, * \mathrm{P}<0.05$, ns $\mathrm{P}$ $>0.05$ ) are shown. Model performance is indicated by the deviance explained (dev. expl.) of the respective models.

\begin{tabular}{|c|c|c|c|c|c|c|}
\hline \multicolumn{2}{|c|}{ Variables } & \multicolumn{2}{|l|}{$\mathbf{T P}_{\text {Mix }}$} & \multicolumn{2}{|l|}{ WT } & \multirow[b]{2}{*}{ dev. expl. } \\
\hline taxon & model & e.d.f. & $F$ & e.d.f. & $F$ & \\
\hline \multirow{3}{*}{ TOTAL } & full & 2.70 & $17.19 * * *$ & 3.96 & $2.87 *$ & $84.4 \%$ \\
\hline & $\mathrm{TP}_{\text {Mix }}$ & 2.79 & $33.26 * * *$ & - & - & $76.1 \%$ \\
\hline & WT & - & - & 3.04 & $9.71 * * *$ & $52.1 \%$ \\
\hline \multirow[t]{3}{*}{ CYA } & full & 2.41 & $25.6 * * *$ & $1.4 \mathrm{e}-05$ & $2.8 \mathrm{e}-05 \mathrm{~ns}$ & $67.7 \%$ \\
\hline & $\mathrm{TP}_{\text {Mix }}$ & 2.41 & $25.6 * * *$ & - & - & $67.7 \%$ \\
\hline & WT & - & - & 2.12 & $5.79 * *$ & $33.2 \%$ \\
\hline \multirow[t]{3}{*}{ CHR } & full & 0.71 & $2.42 \mathrm{~ns}$ & 0.78 & $3.54 \mathrm{~ns}$ & $26.8 \%$ \\
\hline & $\mathrm{TP}_{\text {Mix }}$ & 2.04 & $5.06 *$ & - & - & $23.8 \%$ \\
\hline & WT & - & - & 1.44 & $7.19^{* *}$ & $25.8 \%$ \\
\hline \multirow[t]{3}{*}{ CDI } & Full & 0.97 & $38.19 * * *$ & 0.29 & $0.43 \mathrm{~ns}$ & $57.4 \%$ \\
\hline & $\mathrm{TP}_{\text {Mix }}$ & 0.98 & $50.13 * * *$ & - & - & $56.7 \%$ \\
\hline & WT & - & - & 2.12 & $8.44 * * *$ & $40.0 \%$ \\
\hline \multirow[t]{3}{*}{ PDI } & full & $1.0 \mathrm{e}-05$ & 7.8 e- 05 & 2.36 & $2.95 *$ & $25.5 \%$ \\
\hline & $\mathrm{TP}_{\text {Mix }}$ & 4.54 & ns & - & - & $24.5 \%$ \\
\hline & WT & - & $1.45 \mathrm{~ns}$ & 2.36 & $2.95 *$ & $0.0 \%$ \\
\hline \multirow[t]{3}{*}{ DIN } & full & 0.64 & $0.87 \mathrm{~ns}$ & 4.7 e- -05 & $3.3 \mathrm{e}-05$ & $5.84 \%$ \\
\hline & $\mathrm{TP}_{\mathrm{Mix}}$ & 0.64 & $1.8 \mathrm{~ns}$ & - & - & $5.84 \%$ \\
\hline & WT & - & - & $2.5 \mathrm{e}-05$ & $2.3 \mathrm{e}-05 \mathrm{~ns}$ & $0.0 \%$ \\
\hline \multirow[t]{3}{*}{ CRY } & full & 2.25 & $11.21 * * *$ & $3.1 \mathrm{e}-05$ & $1.09 \mathrm{e}-07$ & $47.7 \%$ \\
\hline & $\mathrm{TP}_{\mathrm{Mix}}$ & 2.25 & $11.21 * * *$ & - & - & $47.7 \%$ \\
\hline & WT & - & - & 1.62 & $3.44 *$ & $19.4 \%$ \\
\hline \multirow[t]{3}{*}{$\mathrm{CHL}$} & full & 2.99 & $39.48 * * *$ & 2.07 & $3.07 *$ & $88.7 \%$ \\
\hline & $\mathrm{TP}_{\mathrm{Mix}}$ & 2.99 & $58.57 * * *$ & - & - & $85.7 \%$ \\
\hline & WT & - & - & 0.96 & $22.47 * * *$ & $37.6 \%$ \\
\hline \multirow[t]{3}{*}{$\mathrm{CON}$} & full & 2.67 & 25.51 & 3.4 e- 05 & $1.3 \mathrm{e}-05 \mathrm{~ns}$ & $70.0 \%$ \\
\hline & $\mathrm{TP}_{\text {Mix }}$ & 2.67 & 25.51 & - & - & $70.0 \%$ \\
\hline & WT & - & - & 2.18 & $8.99 * * *$ & $42.1 \%$ \\
\hline
\end{tabular}




\title{
Compensatory dynamics and the stability of phytoplankton biomass during 4 decades of eutrophication and oligotrophication
}

\author{
Marc Jochimsen $^{1}$, Reiner Kümmerlin ${ }^{2}$ \& Dietmar Straile ${ }^{1}$ \\ 1 Limnological Institute, University of Konstanz, 78464 Konstanz, , Germany \\ 2 Institut für Seenforschung, 88085 Langenargen, Germany
}

Appendix S4 Results of 'expanding window' and 'moving window' analyses with biomasses of the year 1988 replaced by average biomasses of the years 1987 and 1989 .
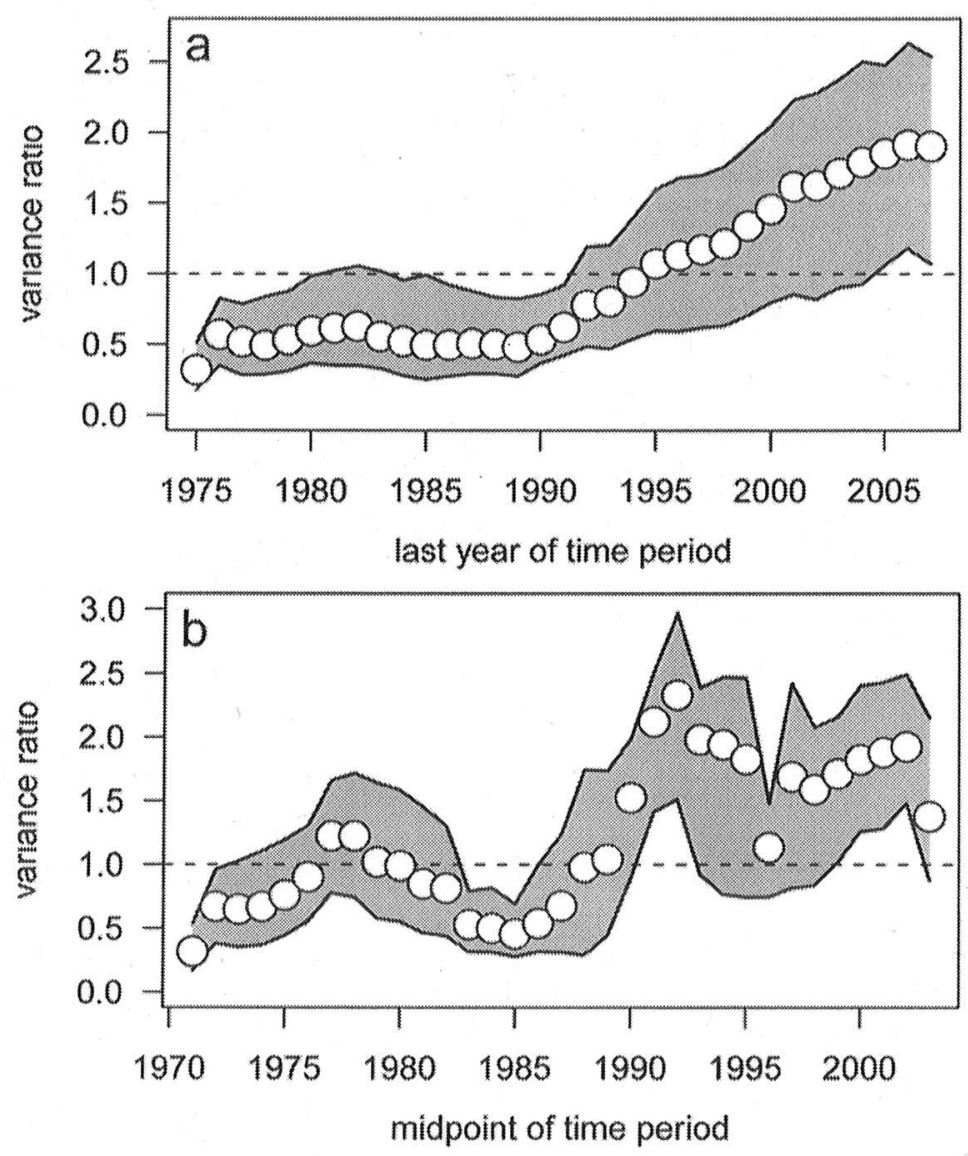

Fig S4-1 a) 'expanding window' analysis of variance ratios, and b) 11-year 'moving window' analysis of variance ratios. In the 'expanding window' analysis the first data point presents the respective value for the period 1965-1975, subsequent ones time periods starting in 1965 and lasting until the year shown on the $\mathrm{x}$ - axis. In the 'moving window' analysis the midpoint of the moving window is shown on the $x$-axis. Vertical lines and shaded areas represent $95 \%$ bootstrap confidence intervals with block resampling (see Appendix S1). The vertical dashed line at VR $=1$ indicates independent dynamics. Biomasses of the year 1988 were replaced by average biomasses of the years 1987 and 1989 in order to demonstrate that the overall VR dynamics is not strongly influenced by the high biomass values of the specific year 1988. 


\title{
Compensatory dynamics and the stability of phytoplankton biomass during 4 decades of eutrophication and oligotrophication
}

\author{
Marc Jochimsen $^{1}$, Reiner Kümmerlin ${ }^{2} \&$ Dietmar Straile $^{1}$ \\ 1 Limnological Institute, University of Konstanz, 78464 Konstanz, , Germany \\ 2 Institut für Seenforschung, 88085 Langenargen, Germany
}

\section{Appendix S5 Factors limiting phytoplankton during the high biomass and low biomass periods}

Lake Constance has traditionally been considered as a predominantly phosphorus limited system (Sommer 1987). Extensive studies by Sommer (Sommer 1983;Sommer \& Stabel 1983;Sommer 1984b;Sommer 1984a;Sommer 1985;Sommer 1986;Sommer 1987) during the eutrophic period revealed that besides phosphorus also silicate, light and grazing limited phytoplankton growth in Lake Constance. Limitation by silicate, light and grazing during the vegetation period is an indirect consequence of high phosphorous input and consequently increased algal biomass. High algal (diatom) biomasses caused increased silicate depletion during the growing season, strong light absorption due to the photosynthetic pigments of algae especially in upper water layers (Tilzer 1983), and high abundances of zooplankton, especially of Daphnia (Straile \& Geller 1998). $\mathrm{CO}_{2}$ has not been considered as a potential limiting factor in the studies undertaken by Sommer (Sommer 1983;Sommer \& Stabel 1983;Sommer 1984b;Sommer 1984a;Sommer 1985;Sommer 1986;Sommer 1987) and unfortunately no measurements on dissolved $\mathrm{CO}_{2}$ concentrations are available. However, as $\mathrm{CO}_{2}$ consumption by algae will increase the $\mathrm{pH}$ of the water column (Wetzel 2001), $\mathrm{pH}$ maxima may be used to infer the severeness of $\mathrm{CO}_{2}$ limitation. Laboratory experiments have shown that especially growth of chrysophyte species is restricted at low $\mathrm{CO}_{2}$, respectively high $\mathrm{pH}$ levels, apparently due to a lack of carbon-concentrating mechanisms used by most other algae and therefore missing access to inorganic carbon sources (Maberly et al. 2009). 
Limnetic enclosure experiments suggest termination of population growth of several chrysophyte species when pH exceeded 8.8 (Reynolds 1986). The reduction of phytoplankton biomass with oligotrophication hence should have resulted into an increased light availability in deeper water layers, increased silicate concentrations due to reduced demand by diatoms, decreased pH maxima and reduced zooplankton, especially Daphnia abundances.

Fig. S5-1 compares the high versus low biomass periods in respect to chl $a$ profiles of the water column, relative occurrences of limiting concentrations of soluble reactive phosphorus and silicate, annual $\mathrm{pH}$ maxima and zooplankton abundance - algal biomass ratios.
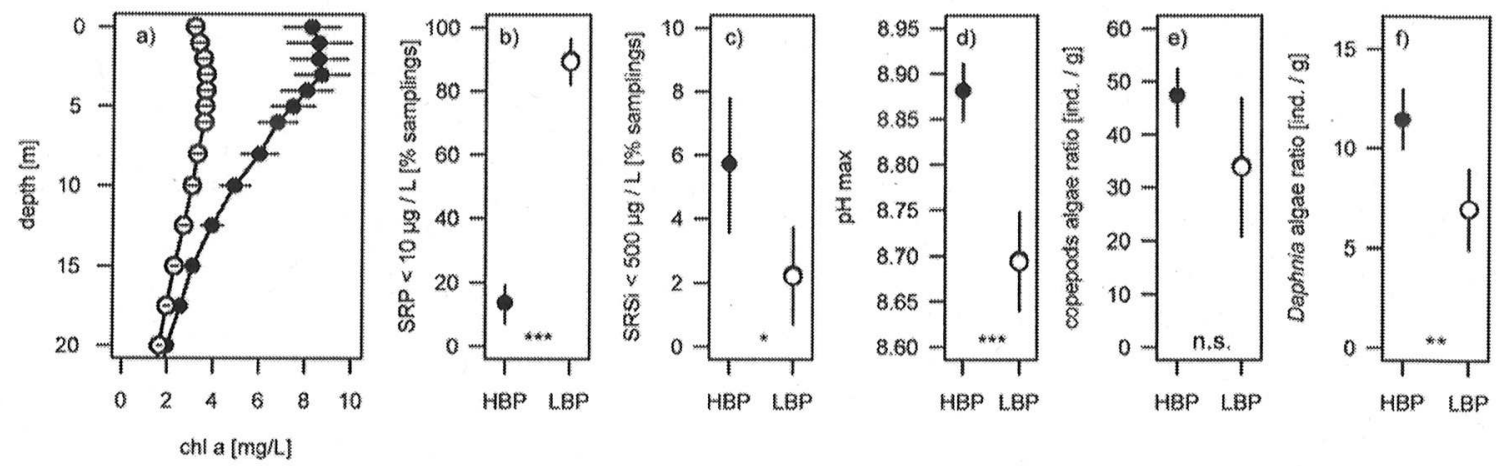

Fig. S5-1 Factors limiting phytoplankton during the high biomass and low biomass periods. a) Mean chlorophyll $a$ profiles during HBP (full symbols) and LBP (open symbols). Horizontal lines indicate \pm 2 standard errors (SE). b) relative frequency of soluble reactive phosphorus measurements below $10 \mu \mathrm{g} / \mathrm{L}$ within the upper 20 of the water column during $\mathrm{HBP}$ and LBP, c) relative frequency of silicate measurements below $500 \mu \mathrm{g} / \mathrm{L}$ within the upper 20 of the water column during HBP and LBP, d) Mean annual $\mathrm{pH}$ maxima during HBP and LBP within the upper $20 \mathrm{~m}$ of the water column. e) Daphnia and f) copepod abundance to algae biomass ratios during HBP and LBP. Vertical bars indicate \pm 2 SE, significance levels are classified as $* \mathrm{p}<0.05, * * \mathrm{p}<0.01, * * * \mathrm{p}<0.001$, n.s. $\mathrm{p}>0.05$

Chl $a$ concentrations have strongly decreased from the HBP to the LBP in the upper water layers suggesting higher light availability below a water depth of e.g. 5 m. However, note that chl $a$ concentrations in the two periods approach each other with increasing depth, i.e., there is no indication that the decline of phytoplankton biomass was due to a vertical displacement of 
phytoplankton biomass beyond the $0-20 \mathrm{~m}$ sampling depth. HBP and LBP differed strongly in respect to the mean relative frequency of limiting soluble reactive phosphorus (SRP) and silicate concentrations in a study year, maximum $\mathrm{pH}$ values in each study year and average Daphnia abundance - phytoplankton biomass ratios, but not in copepod abundance phytoplankton biomass ratios. While SRP concentrations during the HBP were below a threshold indicating phosphorus limitation (Sommer et al. 1993) on average during $15 \%$ of measurements within a year, this value rose to an average of $90 \%$ during the LBP indicating that phosphorus was at concentrations limiting phytoplankton growth almost during all measurements within the upper $20 \mathrm{~m}$ of the water column during this period. In contrast, relative frequencies of silicate measurements below a threshold indicating silicate limitation (Thackeray et al. 2008) decreased approximately 3-fold from the HBP to the LBP. Likewise yearly $\mathrm{pH}$ maxima declined and daphnids declined disproportionately as compared to phytoplankton biomass from the HBP to the LBP. Note that daphnids are considered to have a much stronger impact on phytoplankton than copepods due to their larger size and higher filtrations rates.

Overall, the results presented here suggest that phytoplankton during the HBP was limited by a multitude of factors including phosphorus, light, herbivory, silicate and possibly $\mathrm{CO}_{2}$; whereas in the LBP phosphorus limitation increased strongly and the importance of other limiting factors has decreased.

\section{References}

Maberly S.C., Ball L.A., Raven J.A. \& Sultemeyer D. (2009) Inorganic Carbon Acquisition by Chrysophytes. Journal of Phycology 45, 1052-1061

Reynolds C.S. (1986) Experimental Manipulations of the Phytoplankton Periodicity in Large Limnetic Enclosures in Blelham Tarn, English Lake District. Hydrobiologia 138, 43-64

Sommer U. (1983) Light, stratification and zooplankton as controlling factors for the spring development of phytoplankton in Lake Constance. Schweiz.Z.Hydrobiol. 45, 394-404 
Sommer U. (1984a) Population dynamics of three planktonic diatoms in Lake Constance. Hol.Ecol. 7, 257-261

Sommer U. (1984b) Sedimentation of principal phytoplankton species in Lake Constance. J.Plankt.Res. 6, 1-14

Sommer U. (1985) Seasonal succession of phytoplankton in Lake Constance. Bioscience 5, $351-357$

Sommer U. (1986) The periodicity of phytoplankton in Lake Constance (Bodensee) in comparison to other deep lakes of Central Europe. Hydrobiol. 138, 1-7

Sommer U. (1987) Factors controlling the seasonal variation in phytoplankton species composition - A case study for a deep, nutrient rich lake. Progress in Phycological Research $5,123-179$

Sommer U., Gaedke U. \& Schweizer A. (1993) The first decade of oligotrophication of lake Constance. II. The response of phytoplankton taxonomic composition. Oecologia 93, 276-284

Sommer U. \& Stabel H.H. (1983) Silicon Consumption and Population-Density Changes of Dominant Planktonic Diatoms in Lake Constance. Journal of Ecology 71, 119-130

Straile D. \& Geller W. (1998) Crustacean zooplankton in Lake Constance from 1920 to 1995: response to eutrophication and reoligotrophication. Arch.Hydrobiol.Spec.Issues Advanc.Limnol. 53, 255-274

Thackeray S.J., Jones I.D. \& Maberly S.C. (2008) Long-term change in the phenology of spring phytoplankton: species-specific responses to nutrient enrichment and climatic change. Journal of Ecology 96, 523-535

Tilzer M.M. (1983) The Importance of Fractional Light-Absorption by Photosynthetic Pigments for Phytoplankton Productivity in Lake Constance. Limnology and Oceanography $28,833-846$

Wetzel R.G. (2001) Limnology - Lake and River Ecosystems, 3rd edn. Academic Press, San Diego. 